\title{
Imagining Zombies
}

\author{
Casey Woodling \\ Coastal Carolina University
}

DOI: $10.2478 /$ disp-2014-0006

BIBLID [0873-626X (2014) 38; pp. 107-116]

\begin{abstract}
Philosophers have argued that the conceivability of philosophical zombies creates problems for physicalism. In response, it has been argued that zombies are not conceivable. Eric Marcus (2004), for example, challenges the conceivability claim. Torin Alter (2007) argues that Marcus's argument rests on an overly restrictive principle of imagination. I agree that the argument relies on an overly restrictive principle of imagination, but argue that Alter has not put his finger on the right one. In short, Marcus's argument fails, but not for the reasons Alter gives.
\end{abstract}

\section{Keywords}

Zombies, conceivability, imagination, first-person perspective, thirdperson perspective

Eric Marcus (2004) challenges the conceivability of philosophical zombies. ${ }^{1}$ Torin Alter (2007) argues that Marcus's argument rests on a questionable assumption, which he calls the entailment principle. ${ }^{2}$

(EP) To imagine the instantiation of a negative property $\mathrm{N}$, one must imagine the instantiation of some positive property $\mathrm{P}$ that entails $\mathrm{N}$. (Alter 2007: 93)

Because this assumption is false, Alter argues, Marcus's conclusion that zombies are inconceivable does not trouble the anti-physicalist argument that depends on the conceivability of zombies. ${ }^{3}$ In this note, I argue that Marcus's argument does not rest on the entailment principle but on the following principle of imagination.

${ }^{1}$ By 'zombies' I mean creatures who are physically, functionally and behaviorally identical to us but not phenomenally conscious.

${ }^{2}$ See Marcus 2004.

${ }^{3}$ See Chalmers 1996.

Disputatio, Vol. VI, No. 38, May 2014

Received: 25/09/2013 Revised: 18/11/2013 Accepted: 24/01/2014 
The principle of imagining subjective properties: To imagine the presence or absence of a subjective property, one must do so from the first-person point of view.

I discuss Alter's response to Marcus and show that it fails to do justice to Marcus's focus on first-person and third-person forms of imagination. I then show that Marcus's argument relies on the principle of imagining subjective properties and argue that this principle is overly restrictive. So, Alter is right that Marcus relies on an overly restrictive assumption, but he has not put his finger on the right one.

\section{Alter's interpretation of Marcus}

Many grant that zombies are conceivable. ${ }^{4}$ Marcus holds that zombies only appear to be conceivable. For him, when one mistakenly believes one has imagined a zombie world, one has actually imagined a world that mirrors ours in terms of its physical, functional, and behavioral properties ${ }^{5}$ and merely refrained from imagining the phenomenal properties of this world. Put another way: claims to conceive of a world identical to ours in terms of physical, functional and behavioral properties but without phenomenal properties are claims about acts or processes of conceiving and not the objects or products of such conceiving. For Marcus, more work needs to be done to conceive of a zombie world. ${ }^{6}$

Alter argues that this demand for more imaginative work rests on the entailment principle.

(EP) To imagine the instantiation of a negative property $\mathrm{N}$, one must imagine the instantiation of some positive property $\mathrm{P}$ that entails $\mathrm{N}$.

\footnotetext{
${ }^{4}$ In this note, I use 'to imagine' and 'to conceive' interchangeably.

${ }^{5}$ In other words, a world with individuals who are like us in terms of their physical constitution, their non-qualitative intentional lives, and their behavior.

${ }^{6}$ In this note, I assume that there is a distinction between phenomenal consciousness and access consciousness. The coherence of the zombie scenario depends on this assumption, so I grant it for the sake of discussion.
} 
According to Alter, Marcus's core idea is that to successfully imagine a zombie world we must imagine a positive property that entails the negative property being a world without phenomenal consciousness. Marcus says there is no such positive property, so we cannot imagine zombies.

To support attributing this principle to Marcus, Alter cites the following.

[E]mpty rooms, empty heads, houses with no one home, and vast stretches of Nebraska are imaginable. In general, empty space is imaginable. In these cases, however, absence is imaginable against the background of presence - the presence of rooms, heads, houses, cows, and, in general, space. But there is nothing comparable in the case of the nothing it's like to be a zombie. There is no inner border or background of inner space against which it is possible to conceive subjective absence. Imagining subjective absence presents an insurmountable obstacle. (Marcus 2004: 483)

Marcus does at times focus on the impossibility of imagining subjective absence. The basic idea here is that to ensure that we have imagined a world that truly lacks phenomenal consciousness, we have to imagine the lack of subjective properties in the world, and Marcus holds that we can do so only from the first-person point of view. According to Marcus when we imagine a scenario from the first-person point of view, we imagine what it is like to occupy some point of view in the scenario. From such a point of view, though, we cannot imagine a lack of phenomenal consciousness; when we take up such a viewpoint we thereby imagine a world with phenomenal properties because imagining first-personally requires the instantiation of some phenomenal properties in the imagined scenario. ${ }^{7}$ This problem, though, has nothing directly to do with imagining a positive property that entails some other negative property. The quote above does mention our ability to imagine the non-existence of some feature against various backdrops, but these examples are supposed to show that the case of imagining zombies from the first-person point

\footnotetext{
${ }^{7}$ It would be possible by Marcus's lights to imagine a world lacking in some of the subjective properties of our world. A world with no color experiences can be imagined from the first-person point of view; some of the phenomenal properties of our world (what it is like to see various colors) are not instantiated. But imagining a complete lack of subjective properties from the first-person point of view is not possible.
} 
of view is distinct from these other examples where we can imagine the lack of some feature from the third-person point of view. Marcus's point is that the difficulty is not simply imagining the absence of some property. As his examples bring out, imagining such absence is often easy. The zombie case is special; to ensure that the world we imagine is one without subjective properties, we must take up the first-person point of view, but in doing so we thereby imagine a world with phenomenal consciousness.

Alter concedes that he may not have put his finger on the correct assumption driving Marcus's argument, suggesting at one point that perhaps it rests on a more specific version of EP.

(EP') To imagine, from the first-person perspective, the instantiation of a negative property $\mathrm{N}$, one must imagine, from that perspective, the instantiation of some positive property P that entails N. (Alter 2007: 94)

This talk of imagining a scenario from the first-person perspective brings us closer to Marcus's actual argument, but the focus on positive and negative properties continues to run interference.

Despite this distracting focus on the entailment principle, Alter does cite the following reminder from Marcus, which makes it clear that the barrier to imagining zombies lies in concerns about imagining zombies from a certain points of view or perspectives and not concerns about the need for some positive property that guarantees a lack of consciousness.

It is worth emphasizing that it is crucial for the argument in favor of the possibility of zombies that the conceivability of zombies be in part a matter of first-person imagining. As I hope is already clear, no purely third-person imagining by itself will conjure up the alleged zombieworld. (Marcus 2004: 483)

The demand here is clearly put in terms of imagining the situation from a specific point of view and not on imagining a positive property that will entail the lack of consciousness. I suspect that Alter let the passage about imagining emptiness against a background of presence drive his interpretation of Marcus's argument. To make proper sense of the argument, though, we have to recognize that the key difficulty in imagining zombies results from Marcus's demand that we imagine zombies from a point of view from which we cannot actually imagine zombies. ${ }^{8}$

${ }^{8}$ For what it is worth, I think that Alter is too quick to dismiss EP. Nothing 
Alter does discuss another potential argument. Here is his characterization.

If, in trying to imagine total subjective absence, we use something of the what-it-is-like variety - a phenomenal quality — then we are not imagining total subjective absence: the phenomenal quality we use is subjectively present. (Alter 2007: 96)

This is closer, but it leaves out Marcus's explanation for why we must use a phenomenal property in imagining total subjective absence. There is no mention of the principle of imagining subjective properties. Without mentioning this principle, Alter attributes a very bad argument to Marcus. On the latest diagnosis, Marcus is quite confused about how imagination works. Alter appears to accuse Marcus of thinking that if we employ the notion of a phenomenal property in imagining some scenario, then there are phenomenal properties instantiated in the scenario. We of course use our concept of a phenomenal property when we imagine the zombie world, but we do not thereby imagine any referents of the concept existing. Imagination often works this way. When I imagine a world in which God does not exist, I employ the concept of God in the act of imagining this world, but it is important that I imagine that the concept has no referent. Marcus's argument would be poor indeed if he were arguing that because we must use the concept of a phenomenal property to imagine the zombie world, we thereby imagine a world with phenomenal properties. ${ }^{9}$

in my own critique of his interpretation hangs on the truth of EP, but I think it is a principle that can protect us from modal error. Take the case of a godless world. Surely we must, in a philosophical context, be able to point to some positive property in the world that entails or guarantees the non-existence of God in order to be sure that we have imagined a godless world. Here is an example: the property of being a world that satisfies the philosophical naturalist's theory of the world.

${ }^{9}$ This is as bad as saying that imagining a world with no such country as the United States involves the concept of the United States and is thereby a world with the actual United States in it. 


\section{First-person and third-person perspectives in imagina- tion and Marcus's argument}

Alter is right to be suspicious that Marcus is indeed working with an overly restrictive principle of imagination; he has just not identified the correct one. One cannot make proper sense of Marcus's argument without appreciating his emphasis on first-person and thirdperson ways of imagining scenarios. I have touched on this distinction. Here is Marcus himself.

The imagined difference between zombies and us is purely first-personal or subjective. What is such a difference? As typically understood, a first-person difference is a difference of what it's like . . . To imagine Abe Lincoln third-personally is to imagine the way his parts are laid out in space. To imagine him first-personally is to consider how the world appeared to him, to imagine feeling what he felt, experiencing his moods, and so forth. To imagine a subjective difference between Abe Lincoln and someone else is to imagine a difference in what it's like to be them. (Marcus 2004: 482)

Here Marcus notes that there are at least two distinct ways one can imagine a world. One can imagine first-personally by placing oneself in the world and imagine experiencing that world. One can imagine third-personally by imagining a world but not imagining what it is like to be in that world. ${ }^{10}$ For example, I can imagine scoring the winning goal of the final of the 2014 World Cup first-personally. I imagine experiencing the elation, joy and adrenaline that results from such a feat. I can imagine that same situation from a thirdperson point of view, too. I picture myself scoring the winning goal in the final of the 2014 World Cup from the point of view of an outsider. ${ }^{11}$ I do not imagine what it's like to do this. I just see myself doing it as spectators in the stands would or perhaps as television viewers would. This distinction between first-person and third-per-

${ }^{10}$ There are interesting things to say here about ways of imagining a scenario. I do not have the space to consider more detailed distinctions. See Shoemaker 1994 and Nagel 1974 for related discussions.

${ }^{11}$ It is perhaps important not to imagine myself doing this from the standpoint of being a spectator, because that may be incoherent. How can I be in the stands and score the winning goal at the same time? To imagine third-personally does not require that one is in the situation at all. One may simply take a God's-eyeview of things wherein one is not located in the scenario at all. 
son imagining does not track whether or not the subject doing the imagining has his or her normal identity in the scenario in question, but whether the subject imagines what it is like to be experiencing a given scenario or whether the subject imagines the situation without imagining directly experiencing the scenario. ${ }^{12}$

Consider the following from Marcus regarding the ability to imagine zombies first-personally.

To imagine zombies first-personally, then, is to imagine what it's like to be a zombie. What is it like to be a zombie? Well, zombies are beings without consciousness. There is nothing that it's like to be a zombie. To imagine zombies first-personally is to imagine first-person nothingness. The difference between Abe and Zombie-Abe is that there is something it's like to be Abe, and nothing it's like to be Zombie-Abe. So, when we add third-person duplication to first-person absence, we've imagined zombies. (Marcus 2004: 482-483)

Imagining zombies first-personally is required to properly imagine zombies according to Marcus, but this is a problem because we cannot imagine first-person absence for the reasons rehearsed earlier.

But why must we imagine zombies from the first-person point of view? Recall the reminder.

It is worth emphasizing that it is crucial for the argument in favor of the possibility of zombies that the conceivability of zombies be in part a matter of first-person imagining. As I hope is already clear, no purely third-person imagining by itself will conjure up the alleged zombieworld.

Marcus references Saul Kripke's conceivability argument against the identity theory here and the fact that being in pain must be imagined from the first-person point of view. The only acceptable method, according to Marcus, for imagining the existence of subjective properties in a scenario is to imagine them from the first person point of view.

Let me lay out the argument.

${ }^{12}$ As Shoemaker (1994) notes, it may not always be possible to imagine oneself being the subject when one imagines what it is like to be the subject of a scenario. For example, I can imagine what it's like for the world's greatest soccer player, Lionel Messi, to dribble by me, an amateur soccer player, while I can also imagine what it is like to be outmaneuvered by him. I do not thereby imagine being myself and being Messi in that scenario. I imagine having the experience myself and I also imagine what it would be like for him to have such an experience. 
(1) One can imagine situations first-personally or third-personally.

(2) Imagined scenarios have subjective and objective properties.

(3) One must imagine the existence or non-existence of the subjective properties of a scenario first-personally.

(4) If zombies are phenomenally conscious, their phenomenal conscious properties are subjective properties.

(5) In order to examine whether or not zombies have phenomenally conscious properties, one must imagine them first-personally.

(6) We cannot imagine zombies first-personally because imagining a scenario from the first-person point of view is thereby imagining a scenario with phenomenal consciousness.

(3) expresses the principle of imagining subjective properties. It is needed for this argument to go through. If (3) is false, then (5) does not follow, and we therefore avoid the difficult Marcus presents.

Marcus does not devote much of an argument to (3). He makes the brief reference to Kripke's conceivability argument, and he also notes that subjective properties "are graspable only from a first-person point of view" (Marcus 2004: 482). We should resist (3), because there is an important distinction Marcus does not draw out, one which is detrimental to his argument.

In one sense, it is true that one must imagine the subjective properties of a scenario from the first-person point of view. To imagine what it is like to skydive, for example, I must do so from the firstperson point of view. In this sense, it is true to say that subjective properties are only graspable from the first-person point of view. However, I need not imagine a situation from the first-person point of view in order to know whether or not subjective properties are instantiated in it. Consider an example. I imagine my brother skydiving for the first time. No matter the detail I add, no matter the objective properties I imagine being instantiated (the location, time, weather conditions, nature of his jump, etcetera), I also imagine that there is something it is like for him to make the jump. In the sce- 
nario there are subjective properties instantiated even though I do not imagine the scenario from the first-person point of view. There is no problem in granting this natural claim. It is not as if I remain in a state of uncertainty about whether my brother as I imagine him has or lacks phenomenal consciousness. From a third-person point of view, I imagine him making the jump and imagine that there is something it is like for him to make the jump — without imagining experiencing those things myself. ${ }^{13}$ Marcus holds that one can only know that a subjective property is instantiated if one imagines experiencing or not experiencing that property directly in the imagined scenario. But there are plenty of cases where we can imagine the characters in imagined situations having experiences even if we ourselves are not imagining ourselves having those very experiences. One need not imagine experiencing a subjective property being instantiated in an imagined scenario to be sure that it is instantiated, as my example shows. Therefore, the principle of imagining subjective properties is an implausible principle of imagination.

Some may reply that the principle of imagining subjective properties is needed to protect against modal error. ${ }^{14}$ How can I be sure that I have imagined a scenario in which there is something it is like for my brother to skydive if I do not imagine — from his own point of view — what it is like or not like for him? Without the space to offer a theory of modal error, let me examine the scope for error in the current example. Despite my claim to have imagined subjective properties from a third-person point of view, I may have actually misdescribed the situation. I described it as one in which my brother does experience skydiving. Perhaps it is a more complicated case, one in which he does skydive but experiences nothing. Let us suppose he has passed out right before the jump. That would be a situation in which he lacks phenomenal consciousness of the jump. But notice what I have done. I have added a supposition to the situation that explains the lack of phenomenal consciousness. As the situa-

\footnotetext{
${ }^{13}$ I may even imagine that he feels scared before the jump, feels exhilarated during the jump, and feels relieved and full of adrenaline after the jump from the third-person point of view. These subjective properties are instantiated in the imagined scenario even though I do not imagine myself having these experiences.

${ }^{14}$ My thanks to an anonymous reviewer for pressing me on this concern.
} 
tion was initially described — without this supposition — it does not seem possible that I could be mistaken. Indeed we can create different scenarios in which there is no phenomenal consciousness, but these are distinct from the original for they build in new details. Imagination may have some similarities to perception, but one thing is for certain: the scope for error in imagination is much narrower than in perception. Error is no doubt possible, but in order to be mistaken about the phenomenal properties in the skydiving scenario, I would need to build more detail into the scenario that explains how my brother fails to experience anything. I need to, in effect, imagine a distinct scenario.

In conclusion, once we properly appreciate the role that first-person and third-person perspectives in imagination play in Marcus's argument, we can see exactly where things go wrong: his implausible view of what is required to reveal the existence of subjective properties in imagined scenarios. While I am somewhat skeptical of our ability to conceive of philosophical zombies, we do not fail to imagine them because we fail to imagine the absence of subjective properties from a perspective that necessarily instantiates such properties, for there is no good reason to hold that we must imagine the instantiation of subjective properties in imagined scenarios only from the first-person point of view. ${ }^{15}$

Casey Woodling Department of Philosophy and Religion Coastal Carolina University PO Box 261954 Conway, SC 29528-6054, USA cwoodling@coastal.edu

\section{References}

Alter, Torin. 2007. Imagining Subjective Absence: Marcus on Zombies. Disputatio Vol. II, No. 22: 91-100.

Marcus, Eric. 2004. Why Zombies are Inconceivable. Australasian Journal of Philosophy 82: 477-490.

Nagel, Thomas. 1974. What Is It Like To Be a Bat? Philosophical Review 83: 435 450 .

Shoemaker, Sydney. 1994. The First-Person Perspective. Proceedings and Addresses of the American Philosophical Association Vol. 68, No. 2: 7-22.

${ }^{15} \mathrm{My}$ thanks to two anonymous reviewers for helpful comments. 